\title{
Life-history characteristics of coral reef gobies. I. Growth and life-span
}

\author{
V. Hernaman ${ }^{1,3, *}$, P. L. Munday ${ }^{2}$ \\ ${ }^{1}$ Department of Marine Science, University of Otago, PO Box 56, Dunedin, New Zealand \\ ${ }^{2}$ School of Marine Biology and Aquaculture, James Cook University, Townsville, Queensland, Australia \\ ${ }^{3}$ Present address: School of Biological Sciences, Victoria University, PO Box 600, Wellington, New Zealand
}

\begin{abstract}
Life-history theory predicts that small species will exhibit short life-spans and fast growth rates; however, previous studies indicate that a positive relationship between size and maximum age may not be universally applicable to coral reef fishes. Here, we investigate the growth and life-span of 5 small species of coral reef goby (family Gobiidae): Istigobius goldmanni, Asterropteryx semipunctatus, Amblygobius bynoensis, Amblygobius phalaena and Valenciennea muralis. All 5 species were relatively short-lived, with the oldest individual sampled ranging from 11 to 16 mo depending on species and sex. Rapid growth occurred over much of the size range of all 5 species and, in contrast to most reef fishes, relatively little or no time was spent at an asymptotic size. Patterns of growth were best described by a Broken Stick model for I. goldmanni, and by either a Broken Stick model or the von Bertalanffy growth function for the other 4 species. Summer-growing individuals had higher growth rates than winter-growing individuals, but this did not affect the overall patterns of growth. Sex-specific differences in growth were evident for I. goldmanni and A. semipunctatus, with males growing faster and attaining a larger maximum size than females. In contrast, there was no significant difference in growth between male and female A. bynoensis, A. phalaena and $V$. muralis. This pattern may be related to interspecific differences in intensity of sexual selection, mating system, and reproductive behaviour. Overall, the patterns of growth and life-span of these 5 small species conformed to traditional concepts of life-history theory.
\end{abstract}

KEY WORDS: Longevity $\cdot$ Growth $\cdot$ Body size $\cdot$ Life history $\cdot$ Gobiidae $\cdot$ Otolith

\section{INTRODUCTION}

Body size and maximum life-span are correlated for a broad range of organisms, including mammals, birds and invertebrates, and in general maximum life-span increases with increasing body size (Blueweiss et al. 1978, Stearns 1992). Additionally, Charnov (1993) observed that, as an important invariant of life history, growth rate is inversely related to asymptotic size. Therefore, small species are typically expected to exhibit short life-spans and fast growth rates, whereas large species are expected to have greater life-spans and slow growth. Whilst many small species of fish are indeed short-lived, some small temperate and tropical species are actually relatively long-lived (Miller 1996, Munday \& Jones 1998), therefore the applicability of general life-history predictions to small reef fish requires further investigation.

The available data suggest that a positive relationship between size and maximum age may not be universally applicable to coral reef fishes (Choat \& Robertson 2002). Firstly, many small species, especially some pomacentrids (e.g. Hill \& Radtke 1988, Worthington et al. 1995, Meekan et al. 2001) and small acanthurids (e.g. Choat \& Axe 1996, Hart \& Russ 1996), are longlived. Secondly, species with similar maximum ages can differ in maximum size by an order of magnitude (Choat \& Robertson 2002). Lastly, within-taxon comparisons indicate that a positive relationship between size and maximum life-span may not always apply. For example, several small species of acanthurids have greater maximum ages than much larger species in the 
same family (Choat \& Robertson 2002), and 3 closely related species of lutjanids that have similar maximum size differ in maximum age by 12 to $19 \mathrm{yr}$ (Newman et al. 1996, 2000). Therefore, size-age relationships may be very complex for coral reef fishes, and more information is required on the growth and life-span of small species to determine to what extent they conform to life-history predictions and generalisations (Munday \& Jones 1998).

An ideal group in which to test life-history predictions for small reef fishes is the family Gobiidae (gobies), which is dominated by species with a maximum total length of less than $100 \mathrm{~mm}$. Despite being among the most diverse and abundant group of coral reef fishes (Leis \& Rennis 1983, Randall et al. 1997, Ackerman \& Bellwood 2000), very little is known about growth rates, patterns of growth and life-span of tropical gobies. Available data suggest that coral reef gobies inhabiting burrows or living in sand/rock habitats may be relatively short-lived $(<2 \mathrm{yr}$; Yanagisawa 1982, Reavis \& Barlow 1998, Kritzer 2002). However, more cryptic species, such as coral-dwelling gobies, appear to have longer life-spans (e.g. $>4$ yr; Munday 2001). Therefore, the type of habitat utilised and its associated predation risk might make an important contribution to the relationship between life-span and body size, as has been highlighted for temperate gobies (Miller 1984) and suggested for tropical gobies (Munday \& Jones 1998).

We investigated growth rates and life-span of 5 common coral reef gobies (Asterropteryx semipunctatus, Istigobius goldmanni, Amblygobius bynoensis, Amblygobius phalaena and Valenciennea muralis) and compared them with predictions from life-history theory. The coral reef gobies in our study are all small species, but the maximum size differs between species, ranging from 45 to $120 \mathrm{~mm}$ total length. These species also differ in their patterns of habitat use, being found amongst coral rubble, in sand/rock habitats or in burrows. Thus, these 5 species provided an ideal opportunity to compare patterns of growth and maximum lifespan in relation to both body size and habitat use.

Growth models are often used to describe patterns of growth, and consideration must be given to choosing an appropriate model. Although often subject to criticism (e.g. Roff 1980), the von Bertalanffy growth function (VBGF), which describes a growth pattern characterised by rapid initial growth that slows towards an asymptotic size, is the most widely used growth curve in the fisheries literature (Chen et al. 1992). The VBGF has been commonly used to describe the growth patterns of long-lived coral reef fishes (e.g. Hart \& Russ 1996, Newman et al. 1996, Gust et al. 2002) that tend to have a relatively brief period of rapid growth followed by an extended period at asymptotic size. However, short-lived fishes might tend to have a prolonged period of rapid growth with relatively little time spent at asymptotic size, and therefore models other than the VBGF might best describe their pattern of growth. For this reason we used a range of growth models to determine the most appropriate descriptor of growth in each of the 5 goby species. Furthermore, males and females often grow at different rates (e.g. Gladstone \& Westoby 1988, Newman et al. 1996, McCormick 1998) and their patterns of growth may be best described by different growth models. Therefore, growth rates, life-span and growth models are examined separately for males and females.

Specifically, we addressed 3 questions for each of the 5 coral reef gobies considered here: (1) What is the maximum life-span, (2) what is the pattern of growth and which is the most appropriate growth model for describing that growth pattern, and (3) are there sexspecific differences in growth rates?

\section{MATERIALS AND METHODS}

Collections. Specimens of each species were collected at intervals from August 1997 to December 1998 from the reef flat at Pioneer Bay, Orpheus Island, Australia $\left(18^{\circ} 35^{\prime} \mathrm{S}, 146^{\circ} 29^{\prime} \mathrm{E}\right)$. Fish were caught using handnets and a clove oil/alcohol mixture (Munday \& Wilson 1997) that caused short-term anaesthesia. Fish were sacrificed by immersion in an ice slurry, blotted dry, measured (total length [TL] and standard length [SL] to the nearest $0.1 \mathrm{~mm}$ ) and weighed (wet weight to the nearest $0.001 \mathrm{~g}$ ). The head was severed from the body and stored in $70 \%$ ethanol. The body, including the reproductive organs, was placed in a solution of $4 \%$ formaldehyde, $5 \%$ glacial acetic acid and 1.3\% calcium chloride (FAACC) for at least $1 \mathrm{wk}$ and then transferred to $70 \%$ ethanol.

Length-weight relationship. To enable sex-specific and interspecific comparisons of growth properties, the relationship between fish length and fish weight was estimated by a power curve, $W=a L^{b}$, where $W$ is weight $(\mathrm{g}), L$ is length $(\mathrm{TL}, \mathrm{mm})$ and $a$ and $b$ are constants.

Estimation of age using counts of otolith growth increments. Sagittal otoliths were extracted from the brain cavity, cleaned, and stored dry in multiwell culture plates until required. To enable enumeration of growth increments, a transverse section of each otolith was prepared. Using thermoplastic glue (crystalbond) as the mounting medium, the otolith was positioned on the end of a glass slide, with the otolith core on the inner edge of the slide. Holding the slide perpendicular to the sand paper, the otolith was then hand-ground using 800 grit sand paper. The crystal- 
bond was softened by reheating on a hotplate and the otolith was repositioned to the middle of a slide with the ground side facing down. The otolith was then hand-ground using 800 grit sand paper and $12 \mu \mathrm{m}$ lapping film until a thin section was obtained that allowed the growth increments to be counted from the core to the edge.

Otolith increments have a daily periodicity in each of the study species (Hernaman et al. 2000), therefore counts of increments provided an estimate of age in days. Counts were conducted using a compound microscope fitted with a polarizing filter. Counts were made on 3 separate occasions, with each count being conducted without reference to previous counts, and the average of the 3 counts used as the age estimate. The otolith was not used if the counts differed by $>10 \%$. To minimise interpretation error (Campana 2001), 2 additional experienced readers counted growth increments on a subset of the sample, including those of Asterropteryx semipunctatus which were the most difficult to read. To examine the precision of age estimates, the coefficient of variation $(\mathrm{CV})$ was determined for each individual, from which a mean $\mathrm{CV}$ was calculated for each species (Campana 2001).

Maximum life-span. The maximum life-span was defined as the age of the oldest fish collected.

Growth pattern. To examine patterns and rates of growth, size-at-age plots were constructed for each species where the age estimate (d) for each individual was plotted against its total length (mm). Two approaches were taken to examine the pattern of growth for each species. Firstly, 4 different growth models were fitted to the size-at-age data, and 3 measures of goodness-of-fit compared for each model: (1) values of the residual sum of squares (RSS), (2) coefficient of determination $\left(\mathrm{r}^{2}\right)$ calculated from the residual and explained sums of squares, and (3) plots of the residuals against age. Secondly, Schnute's (1981) model was fitted to the size-at-age data, and the most appropriate growth model selected according to the estimated values of the model parameters, $a$ and $b$. For each species, the value of parameter a was a small positive or negative value. Whether the value was interpreted as being equal to zero affected the selection of the most appropriate model. To test the null hypothesis that $a=0$, Schnute (1981) suggests fitting a second growth model (which does not incorporate the parameter a) to the data and examining the variance ratio defined by the residual sum of squares for Model 2 divided by the sum of squares for Model 1. The variance ratio is approximately $F$-distributed with the appropriate degrees of freedom under the null hypothesis that $a=0$. Therefore, if the $F$-statistic is greater than the variance ratio, the null hypothesis is retained.
We used 2 models that can describe asymptotic growth, the VBGF:

$$
L_{t}=L_{\infty}\left(1-\mathrm{e}^{-k\left(t-t_{0}\right)}\right)
$$

and the Richards growth model:

$$
L_{t}=L_{\infty}\left(1+[1 / p] \mathrm{e}^{-k\left(t-t_{0}\right)}\right)^{-p}
$$

where $L_{t}$ is mean length at age $t_{1} L_{\infty}$ is the mean asymptotic length, $k$ is the growth coefficient that describes the rate at which the asymptotic size $\left(L_{\infty}\right)$ is approached, and $p$ is the shape parameter for the Richards model. For the VBGF, $t_{0}$ is the theoretical age at which length is zero, but for the S-shaped Richards growth model $t_{0}$ corresponds to an inflection point on the curve. These 2 models were chosen because they describe different patterns of growth in the early life stages. The VBGF describes an initial period of rapid growth that then reaches an asymptote, whereas the Richards model describes an S-shaped growth curve with the most rapid growth appearing in the middle of the growth pattern. This type of growth could occur when newly settled fish have a period of slow growth following settlement.

We also used 2 non-asymptotic growth models, the Power curve (described as: $L_{t}=a\left[t^{b}\right]$, where $a$ and $b$ are constants, and $L_{t}$ is mean length at age $t$ ), and the Broken Stick regression (sometimes referred to as Breakpoint regression) which fits 2 linear models to the data by determining a breakpoint, $x_{0}$. All fish aged $<x_{0}$ have the equation $y=a+b x$ fitted to the size-at-age data, whilst all fish aged $>x_{0}$ have the equation $y=C+$ $d x$ fitted. The parameters $a$ and $c$ are points on the $y$ axis where the 2 linear models cross the $y$-axis, $b$ and $d$ describe the slope of each linear regression. The breakpoint, $x_{0}$, is defined as: $x_{0}=(a-c) /(d-b)$. The Broken Stick regression was selected in place of a linear model because, even for species that had indeterminate adult growth, the rate of adult growth was slower than for the early life-stages, meaning that 1 linear model could not adequately describe both juvenile and adult growth. The Broken Stick regression was fitted to the size-at-age data using an SAS programme written by Brian Niven (Department of Maths and Statistics, University of Otago, New Zealand). The remaining models were fitted using least-squares nonlinear regression with the Gauss-Newton algorithm in the statistical package SYSTAT 10.

Initially, the 4 growth models were fitted separately to male and female size-at-age data for each species, and their goodness-of-fit examined. We then tested for sex-specific differences in growth and, where none were found, fitted the 4 growth models to combinedsex data. For brevity and clarity, we present growth models fitted only to combined-sex data for species where analysis indicated there were no sex-specific differences in rates or patterns of growth. Fish were 
sexed by the shape and size of the genital papilla (short and blunt in females, long and tapered in males) and/or by macroscopic and histological examination of the gonads. It was sometimes difficult to sex small juveniles, even using histological techniques, and these individuals were included in both male-only and female-only data when fitting growth models to the size-at-age data. Specifically, this meant individuals aged $<120 \mathrm{~d}$ for Asterropteryx semipunctatus, $<141 \mathrm{~d}$ for Istigobius goldmanni, $<100 \mathrm{~d}$ for Amblygobius bynoensis, $<72 \mathrm{~d}$ for Amblygobius phalaena, and $<76 \mathrm{~d}$ for Valenciennea muralis.

To test the null hypothesis of no significant difference between male and female growth patterns, 1 of 2 methods was employed depending on the pattern of growth. (1) Analysis of covariance (ANCOVA) was used for species with linear adult growth. Using this method, we compared the slopes of linear regressions fitted separately to adult male and female size-at-age data. (2) For species with attenuating adult growth, a comparison of growth curves between sexes was made using the methods of Chen et al. (1992) and Kimura (1980). Firstly, analysis of residual sum of squares (ARSS) (Chen et al. 1992) was used to determine whether the use of separate growth curves for females and males provided a better fit than 1 common growth curve. Secondly, to examine differences in specific growth characteristics, 95\% confidence ellipses were generated around the parameter estimates of $k$ and $L_{\infty}$ (parameters of the VBGF) for each sex, with $t_{0}$ constrained to a common value (Kimura 1980). Non-overlapping confidence ellipses were considered to indicate a significant difference between sexes in these 2 parameters (Kimura 1980). To estimate a common value for $t_{0}$, the VBGF was fitted to the size-at-age data for males and females separately, allowing the model to provide estimates for all 3 parameters $\left(L_{\infty}, k\right.$ and $\left.t_{0}\right)$. The $t_{0}$ of males and females was then averaged to provide a common value. Using an average value ensured equal bias in deviation from the original $t_{0}$ for both sexes. The value of $t_{0}$ obtained for males and females was often very similar (i.e. within 0.01 and 8.57 of each other depending on species) and, therefore, the impact of using an average $t_{0}$ value calculated in this manner was minimal.

Seasonal comparison of growth. Inspection of the size-at-age data suggested a possible seasonal influence on growth rate for some species. To test this possibility, the techniques of Kimura (1980) were used to compare growth curves between seasons. The year was divided into periods of increasing (September to February) and decreasing (March to August) seawater temperatures based on average monthly seawater temperatures at Pioneer Bay recorded by the Great Barrier Reef Marine Park Authority (www.gbrmpa.gov.au/corp_site/info_services/science/ seatemp). Average monthly seawater temperature varied annually by 7.5 to $9.0^{\circ} \mathrm{C}$ (maximum average monthly temperature $30.3^{\circ} \mathrm{C}$, minimum $21.3^{\circ} \mathrm{C}$ ) over the study period. The months over which each individual had grown were determined by subtracting its estimated age (minus the period from hatching to settlement) from its date of capture. Individuals were then classified according to whether their growth had occurred predominantly or wholly through either summer or winter. Older individuals that had experienced growth in both seasons were categorised according to the season in which most of their initial growth had occurred, as the faster growth rates experienced by juveniles and small adults were presumed to have a larger effect on final size-at-age than growth experienced later in life.

\section{RESULTS}

\section{Length-weight relationship}

The maximum size of male and female Asterropteryx semipunctatus and Istigobius goldmanni were more dissimilar than the maximum size of male and female Amblygobius bynoensis, Amblygobius phalaena and Valenciennea muralis (Table 1). The largest male $A$. semipunctatus and I. goldmanni were 24 and $16 \%$ larger respectively than the largest females. In contrast, the largest male $A$. bynoensis and $V$. muralis were only 4 and $3 \%$ larger respectively than the largest females. The largest female $A$. phalaena was $2 \%$ larger than the largest male.

Table 1. Maximum body size (total length, $\mathrm{mm}$ ) and length-weight relationships of male and female coral reef gobies. Provided are the coefficient of determination $\left(\mathrm{r}^{2}\right)$ and estimates of the parameters $a$ and $b$ from the relationship $W=a L^{b}$, where $W$ is weight and $L$ is length. M: male; F: female; $\mathrm{n}$ : number

\begin{tabular}{|lcccccc|}
\hline Species & Sex & Max. & \multicolumn{6}{c|}{ Length-weight relationship } \\
& & size & $\mathrm{n}$ & $\mathrm{a}$ & $b$ & $\mathrm{r}^{2}$ \\
& & $(\mathrm{~mm})$ & \multicolumn{5}{c}{$\left(\times 10^{-5}\right)$} & & \\
\hline Asterropteryx & $\mathrm{M}$ & 56 & 138 & 0.95 & 3.10 & 0.989 \\
semipunctatus & $\mathrm{F}$ & 45 & 139 & 0.32 & 3.42 & 0.974 \\
Istigobius & $\mathrm{M}$ & 64 & 99 & 1.07 & 2.99 & 0.991 \\
goldmanni & $\mathrm{F}$ & 55 & 86 & 0.61 & 3.15 & 0.969 \\
Amblygobius & $\mathrm{M}$ & 98 & 64 & 0.96 & 3.01 & 0.988 \\
bynoensis & $\mathrm{F}$ & 94 & 64 & 0.82 & 3.06 & 0.991 \\
Amblygobius & $\mathrm{M}$ & 102 & 58 & 1.33 & 2.96 & 0.989 \\
phalaena & $\mathrm{F}$ & 105 & 57 & 1.07 & 3.01 & 0.996 \\
Valenciennea & $\mathrm{M}$ & 116 & 71 & 1.32 & 2.84 & 0.989 \\
muralis & $\mathrm{F}$ & 113 & 98 & 0.73 & 3.00 & 0.932 \\
\hline
\end{tabular}


Length-weight relationships displayed predictable values, with $b$ (where $W=a L^{b}$ ) ranging from 2.84 to 3.42 (Table 1). Females tended to be heavier than males (Table 1), although the difference was least for both Amblygobius species, intermediate for Istigobius goldmanni and $V$. muralis, and most pronounced for Asterropteryx semipunctatus.

\section{Precision of age estimates}

The age estimates for all species generally had a very high level of precision. The CV for each individual ranged from 0 to $16 \%$, but was generally $\leq 4 \%$. The value of the $\mathrm{CV}$ was not related to fish age nor fish size in any of the species. The mean CV per species ranged from 1.95 to $2.79 \%$, depending on species, with the highest CV associated with Asterropteryx semipunctatus and Istigobius goldmanni.

\section{Maximum life-span}

All 5 species were relatively short-lived, with the oldest individual in the sample ranging from 11 to 16 mo depending on species and sex (Table 2).

\section{Growth patterns}

All 5 gobies invested a large proportion of their lifespan in somatic growth, with growth occurring over much of their size range, and relatively little or no time

Table 2. Maximum life-span of 5 coral reef gobies (defined as the age of the oldest individual sampled), and the average proportion of the maximum size attained by half of the maximum life-span. M: male; F: female; n: number

\begin{tabular}{|lcccc|}
\hline Species & Sex & $\mathrm{n}$ & $\begin{array}{c}\text { Age of } \\
\text { oldest } \\
\text { individual } \\
\mathrm{d}(\mathrm{mo})\end{array}$ & $\begin{array}{c}\text { \% of maximum } \\
\text { size attained by } \\
\text { half of maximum } \\
\text { life-span }\end{array}$ \\
\hline $\begin{array}{lcccc}\text { Asterropteryx } \\
\text { semipunctatus }\end{array}$ & $\mathrm{M}$ & 92 & $457(16)$ & 63 \\
Istigobius & $\mathrm{M}$ & 80 & $419(14)$ & 73 \\
goldmanni & $\mathrm{F}$ & 66 & $323(11)$ & 65 \\
Amblygobius & $\mathrm{M}$ & 75 & $377(13)$ & 65 \\
bynoensis & $\mathrm{F}$ & 78 & $349(12)$ & 60 \\
Amblygobius & $\mathrm{M}$ & 64 & $400(14)$ & 64 \\
phalaena & $\mathrm{F}$ & 70 & $414(14)$ & 66 \\
Valenciennea & $\mathrm{M}$ & 68 & $345(12)$ & 64 \\
muralis & $\mathrm{F}$ & 87 & $363(12)$ & 63 \\
\hline
\end{tabular}

spent at asymptotic size (Figs. 1 to 5: note that separate-sex data are presented for Asterropteryx semipunctatus and Istigobius goldmanni, because a sexspecific difference in growth was evident for these 2 species, see below). The 5 species showed similar growth rates in relation to their maximum life-span with generally about $2 / 3$ of their maximum size attained by half of their maximum life-span (Table 2).

Adult growth was linear for Istigobius goldmanni (Fig. 2), and the Broken Stick regression was clearly the best descriptor of growth for both sexes (Fig. 2, Tables 3 \& 4). Growth of Asterropteryx semipunctatus, Amblygobius bynoensis, Amblygobius phalaena and Valenciennea muralis attenuated near the maximum size of each species (Figs. 1 \& 3 to 5). Consequently, growth patterns were neither completely linear nor asymptotic, and both the Broken Stick regression and the VBGF adequately described the growth pattern of these 4 species (Figs. $1 \& 3$ to 5, Tables $3 \& 4$ ).

\section{Asterropteryx semipunctatus}

The size-at-age relationship showed a period of rapid juvenile growth followed by a decrease in growth rate in fish over $150 \mathrm{~d}$ old, and growth attenuating at ca. $330 \mathrm{~d}$ (females) or $350 \mathrm{~d}$ (males) (Fig. 1). The VBGF was the best descriptor of growth for females, with an even distribution of residuals throughout the life-span and the lowest RSS (Table 4, Fig. 1). All models gave a poorer description of male growth. In particular, all models tended to overestimate the size of males aged 200 to $300 \mathrm{~d}$ and $>400 \mathrm{~d}$, and tended to underestimate the size of males aged 300 to 400 d (Fig. 1). The Broken Stick regression and VBGF had the best combinations of low RSS, high $\mathrm{r}^{2}$ and most even distribution of residuals (Table 4, Fig. 1). It was difficult to distinguish between these models; however, fitting Schnute's (1981) model to the size-at-age data suggested that the VBGF was likely to be the best descriptor of growth for both males and females (Table 3).

\section{Istigobius goldmanni}

This species exhibited a 2-phase, linear pattern of growth (Fig. 2a), with a period of rapid growth from settlement to ca. $125 \mathrm{~d}$ old, followed by a second period of slower linear growth. Consequently, the best descriptor of growth for both sexes was the Broken Stick regression (Fig. 2, Tables 3 \& 4). The other 3 models first over- then underestimated the size of individuals $<110 \mathrm{~d}$ old (Fig. 2). For both sexes, fitting the Broken Stick regression to the size-at-age data resulted in 

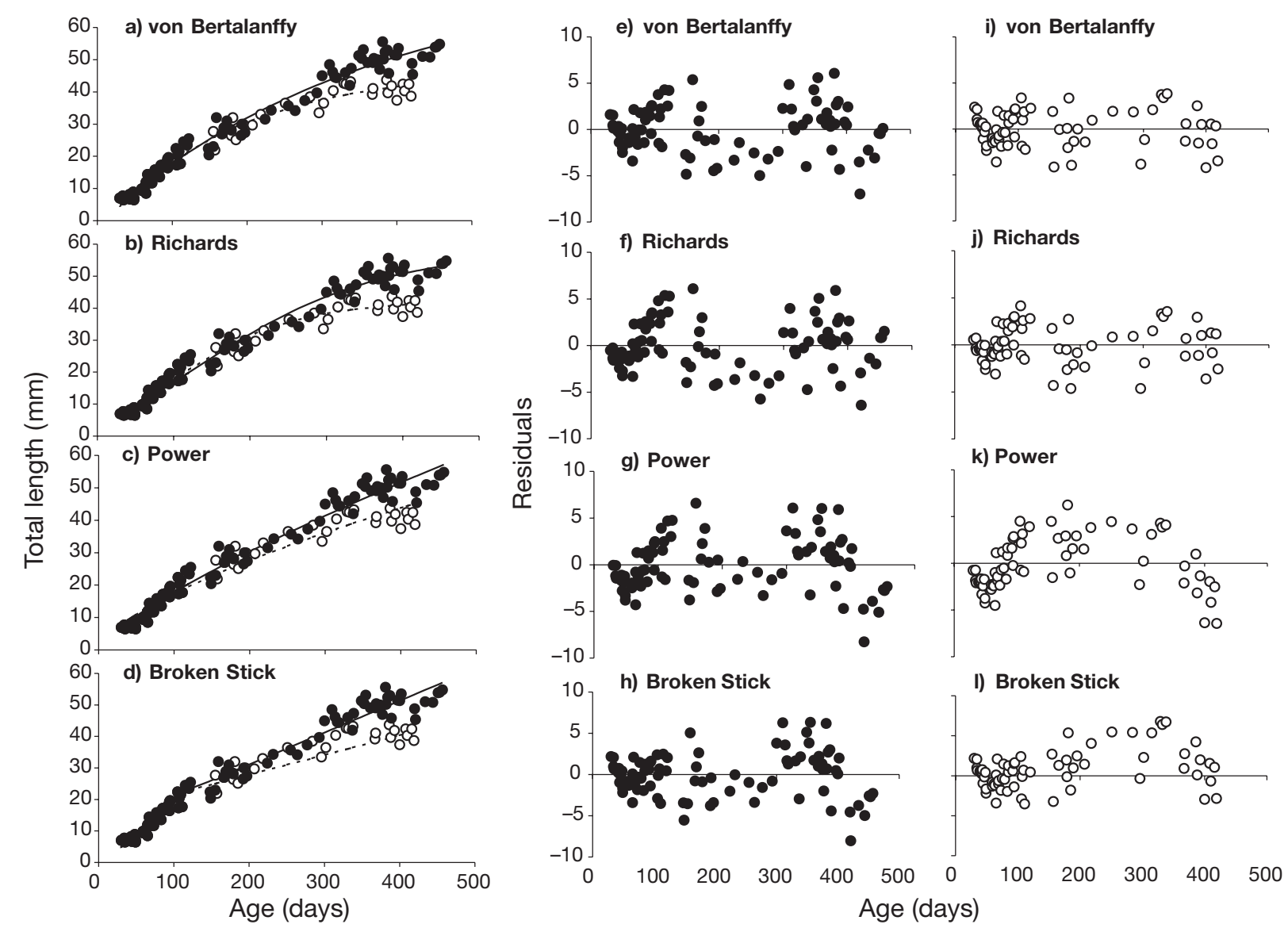

Fig. 1. Asterropteryx semipunctatus. Growth models (a-d) fitted to male (•) and female (O) size-at-age data, and resulting residuals (e-l). Unsexed juveniles used in both male and female data sets

the lowest RSS (Table 4). The RSS obtained from fitting the VBGF was not dramatically higher than that obtained from fitting the Broken Stick regression. However, the VBGF was only able to provide a reasonable description of growth for Istigobius goldmanni by using unreasonably large predicted values of $L_{\infty}(98.1$ and $64.8 \mathrm{~mm}$ TL for males and females respectively), which were much greater than the maximum size of this species at Orpheus Island (64 and $56 \mathrm{~mm}$ TL for males and females, respectively). Fitting Schnute's model to the size-at-age data confirmed that a nonasymptotic growth model was likely to be the best descriptor of growth, with an exponential and a linear model suggested for males and females respectively (Table 3).

\section{Amblygobius bynoensis}

Both the Broken Stick regression and the VBGF adequately described growth in this species (Fig. 3, Tables 3 \& 4). Both models gave a similar distribution of residuals with age (Fig. 3). Although the Broken Stick regression gave the lowest RSS (Table 4) and fitting Schnute's model to the size-at-age data suggested a linear model would be best (Table 3), the VBGF was also considered an appropriate descriptor of growth because examination of the data points suggests an attenuation of growth for fish $>250 \mathrm{~d}$ old (Fig. 3).

\section{Amblygobius phalaena}

Adult growth attenuated in the later stages (i.e. after $\sim 300 \mathrm{~d}$ old) and, consequently, both the asymptotic models and the Broken Stick regression adequately described the pattern of growth from newly settled through to the largest/oldest individuals (Fig. 4). These models gave comparable $\mathrm{r}^{2}$ values (Table 4) and an even distribution of residuals (Fig. 4). The VBGF had the lowest RSS, and fitting Schnute's (1981) model to the size-at-age data suggested that the VBGF was likely to be the best descriptor of growth (Table 3). 

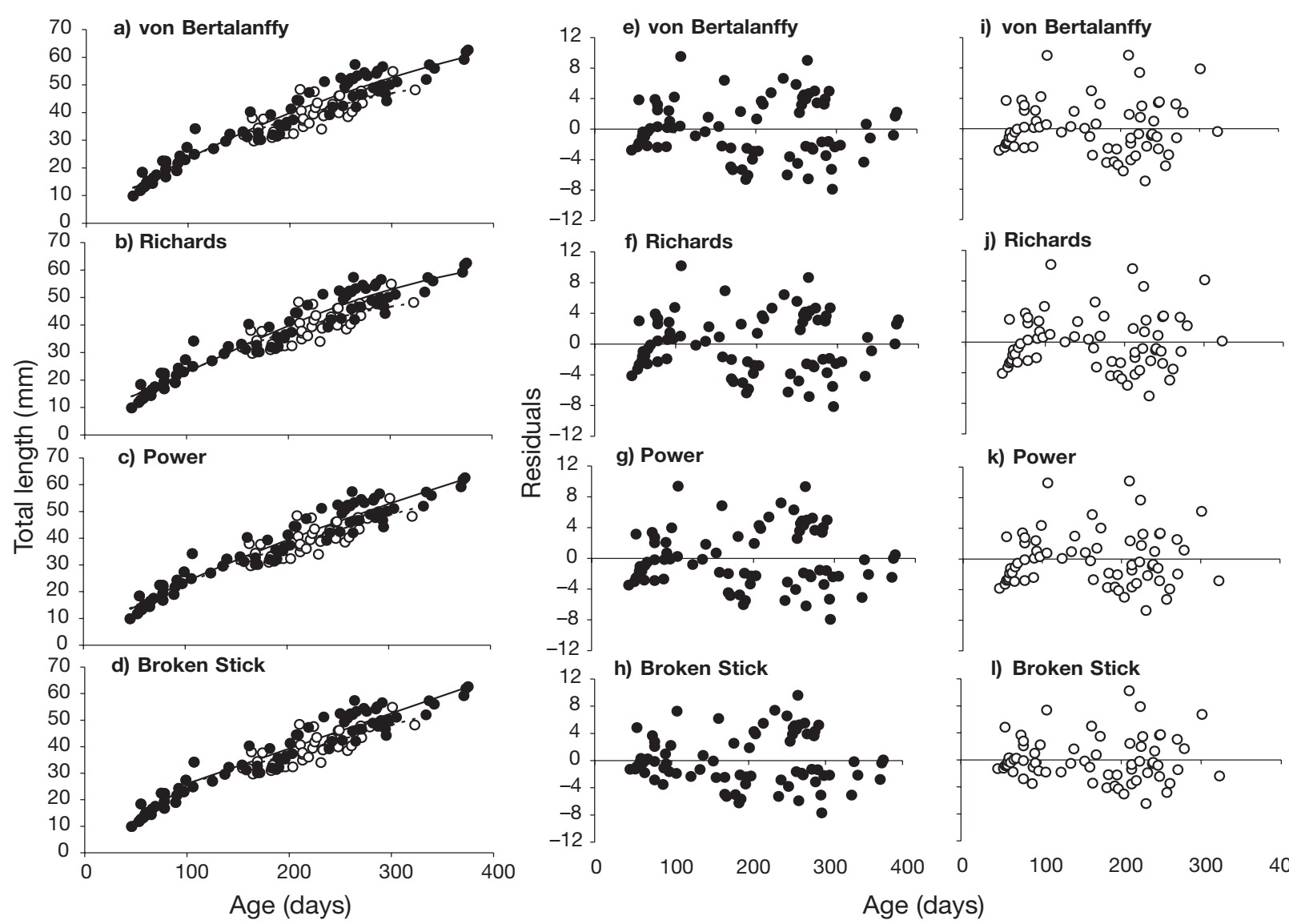

h) Broken Stick

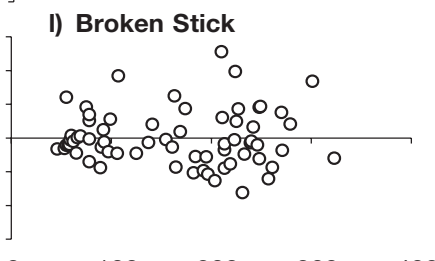

Fig. 2. Istigobius goldmanni. Growth models $(\mathrm{a}-\mathrm{d})$ fitted to male $(\bullet)$ and female (O) size-at-age data, and resulting residuals (e-l). Unsexed juveniles used in both male and female data sets

\section{Valenciennea muralis}

This species showed a period of linear growth from settlement to ca. 150 d old, followed by a period of slower growth (Fig. 5). All 4 models, and especially the Power curve, generally overestimated the size of young juveniles, but both the Broken Stick regression and the VBGF were equally able to describe growth throughout most of the life-span. These 2 models had a similar distribution of residuals (Fig. 5), and comparable RSS and $\mathrm{r}^{2}$ values (Table 4 ). In contrast to Istigobius goldmanni, the VBGF provided an adequate description of growth without assuming an unrealistic asymptotic size (Table 4). However, fitting Schnute's (1981) model to the size-at-age data suggested that a linear model would be the most appropriate descriptor of growth (Table 3).

\section{Limitations of the Power curve}

The Power curve provided the poorest (for 3 species) or second poorest (remaining 2 species) fit to the size- at-age data in terms of RSS and $\mathrm{r}^{2}$ values (Table 4). While it should be acknowledged that the Power curve has fewer parameters than the other models, and thus is at a disadvantage in terms of RSS and $r^{2}$ values, the residual plots indicate that the Power curve was unable to adequately describe the growth throughout the entire life-span of any species. In particular, it often over-estimated the size of individuals at both ends of the life-span (i.e. the youngest and oldest individuals) resulting in a convex distribution of residuals (e.g. Figs. 1k, $3 \mathrm{~g} \& 4 \mathrm{~g})$.

\section{Sex-specific differences}

A sex-specific difference in growth was evident for Istigobius goldmanni (ANCOVA; $F_{1,87}=9.71, \mathrm{p}=$ 0.002) and Asterropteryx semipunctatus (ARSS; p < 0.0001). Male I. goldmanni grew at a significantly faster rate (mean adult growth rate: $0.13 \mathrm{~mm} \mathrm{~d}^{-1}$ ) than females $\left(0.11 \mathrm{~mm} \mathrm{~d}^{-1}\right)$ and attained a larger maximum size than females (Fig. 6). Similarly, male A. semipunctatus attained a larger maximum size than females, 


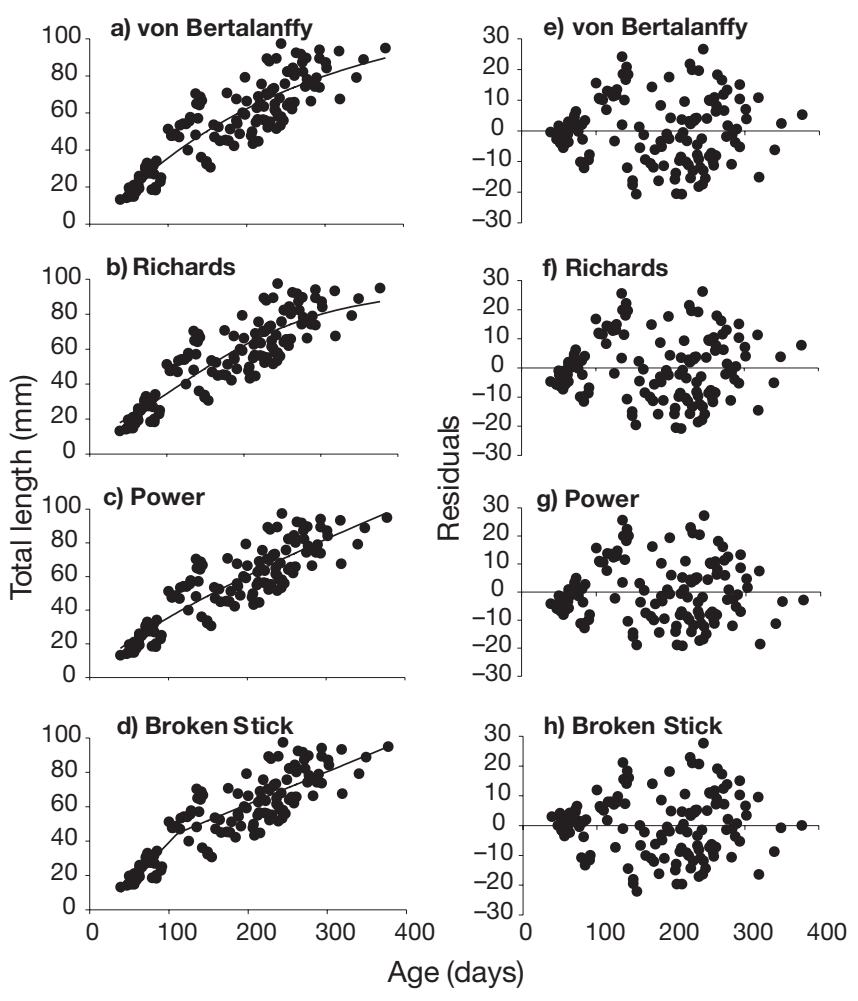

Fig. 3. Amblygobius bynoensis. Growth models (a-d) fitted to size-at-age data, and resulting residuals $(\mathrm{e}-\mathrm{h})$. Sexes are not differentiated because sex-specific differences in growth were not evident

and non-overlapping $95 \%$ confidence ellipses indicated significant sex-specific differences in the parameter estimates of $k$ and $L_{\infty}$ (Fig. 6). There was no significant difference between male and female growth for the 3 remaining species (ARSS: Amblygobius bynoensis, $\mathrm{p}=0.668$; Amblygobius phalaena, $\mathrm{p}=$ 0.868; Valenciennea muralis, $\mathrm{p}=0.729$ ) and overlapping $95 \%$ confidence ellipses generated for $k$ and $L_{\infty}$ indicated similar values of these 2 parameters for males and females (Fig. 6).

\section{Seasonal comparison of growth}

Amblygobius bynoensis exhibited considerable variability in size-at-age (Fig. 3), and when counting otolith growth increments for this species, it was common to observe transitions from wide growth incre-

Fig. 5. Valenciennea muralis. Growth models (a-d) fitted to size-at-age data, and resulting residuals $(\mathrm{e}-\mathrm{h})$. Sexes are not differentiated because sex-specific differences in growth were not evident
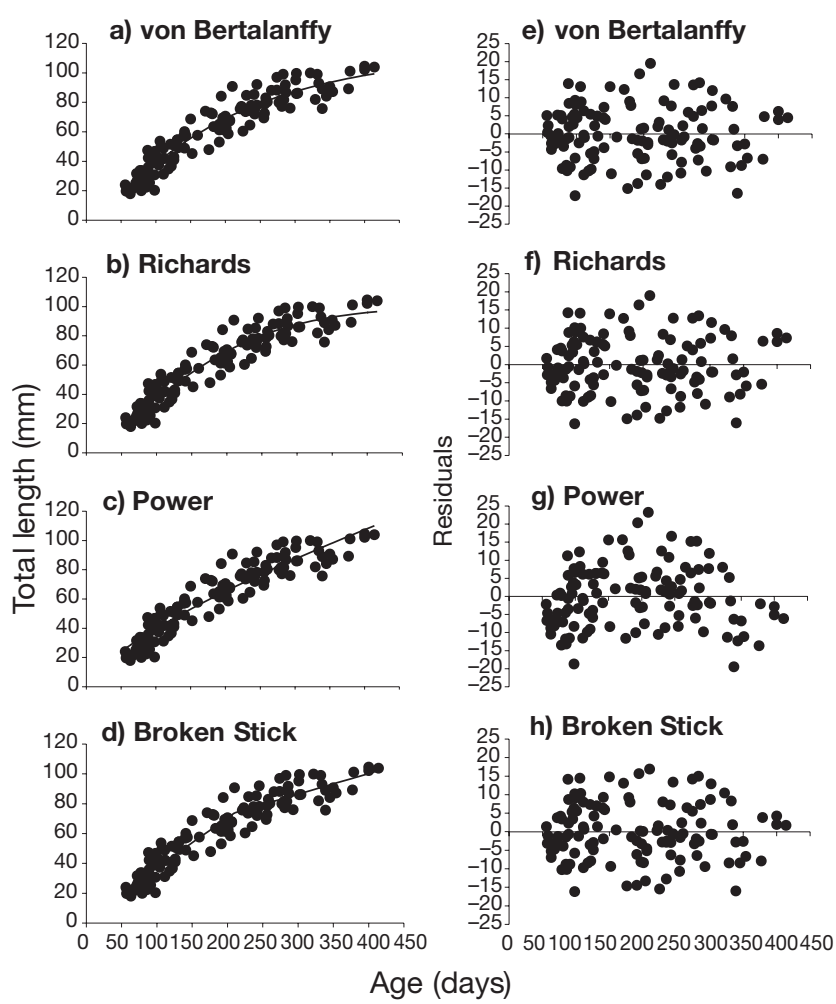

Fig. 4. Amblygobius phalaena. Growth models (a-d) fitted to size-at-age data, and resulting residuals $(\mathrm{e}-\mathrm{h})$. Sexes are not differentiated because sex-specific differences in growth were not evident
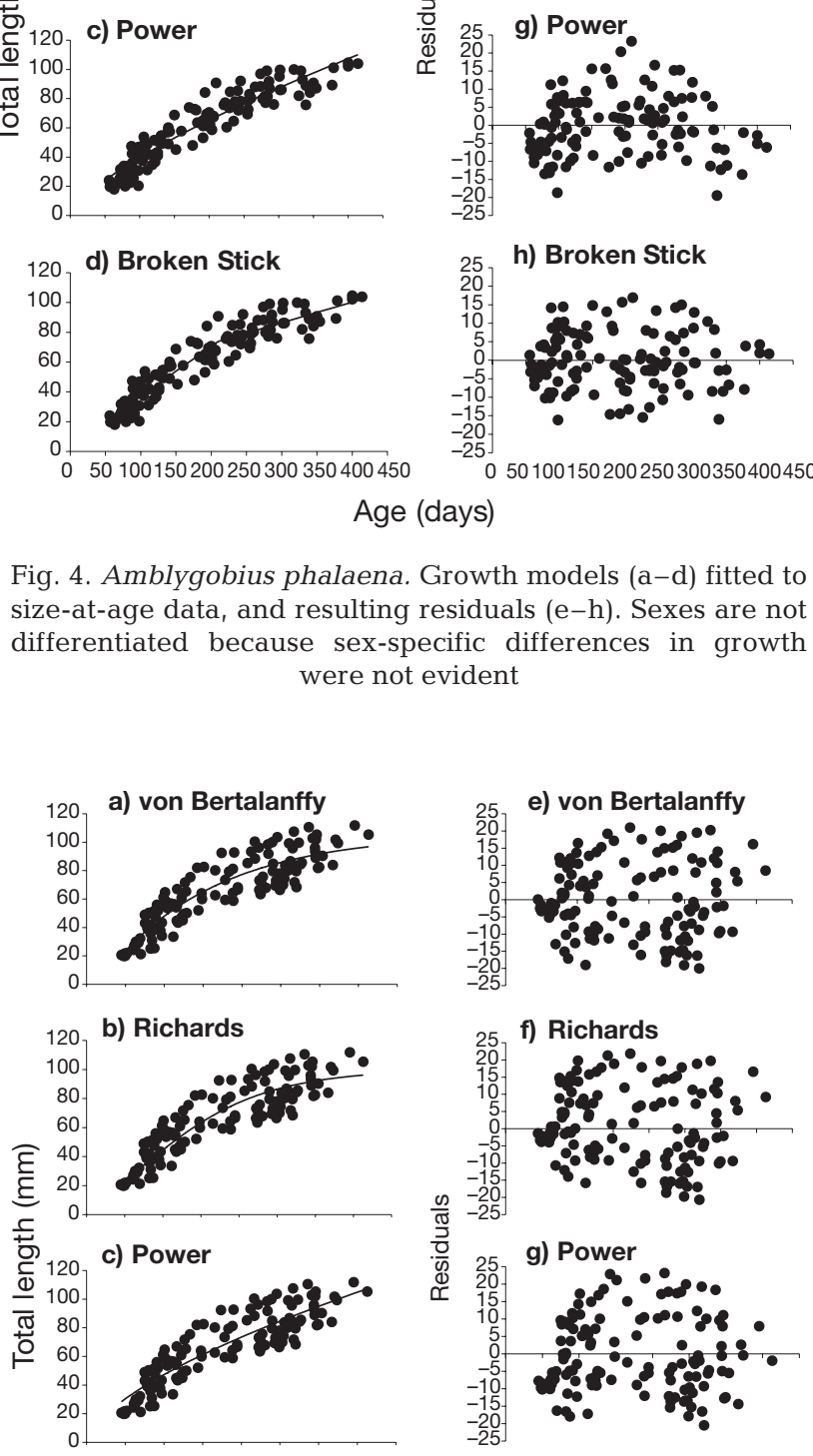

h) Broken Stick
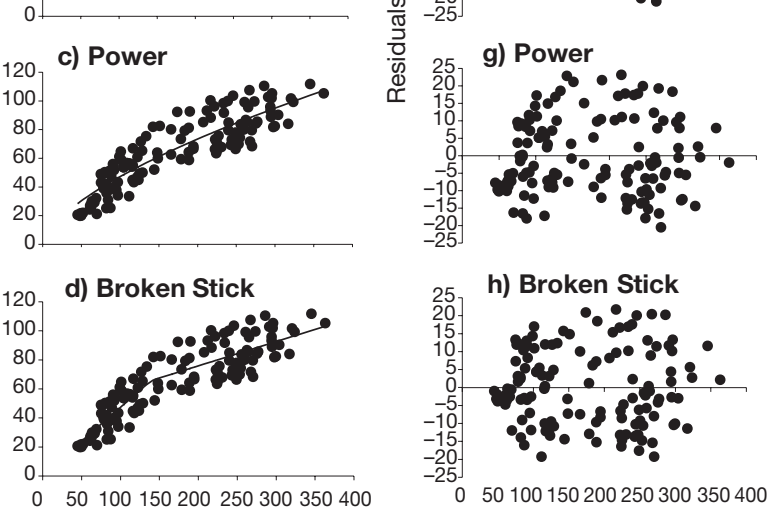

Age (days) 
Table 3. Results of fitting Schnute's (1981) model to the size-at-age data for each of the 5 goby species, and the growth pattern suggested from fitting 4 growth models to the data. Separate sexes given for Asterropteryx semipunctatus and Istigobius goldmanni because sex-specific differences in growth were evident for these 2 species. VB: von Bertalanffy; BS: Broken Stick; Exp:

Exponential; Lin: Linear. M: male; F: female

\begin{tabular}{|c|c|c|c|c|c|c|}
\hline Species & Sex & $\begin{array}{r}\text { Val } \\
\text { Schnut } \\
\text { model p } \\
b\end{array}$ & $\begin{array}{l}\text { ues of } \\
\text { e's (1981) } \\
\text { arameters } \\
\qquad a\end{array}$ & $\begin{array}{l}\text { Test for significant } \\
\text { deviation } \\
\text { of } a \text { from zero }\end{array}$ & $\begin{array}{c}\text { Growth model } \\
\text { suggested by } \\
\text { Schnute's (1981) model }\end{array}$ & $\begin{array}{l}\text { Growth model } \\
\text { suggested by model } \\
\text { fit to the data }\end{array}$ \\
\hline $\begin{array}{l}\text { Asterropteryx } \\
\text { semipunctatus }\end{array}$ & $\begin{array}{l}M \\
F\end{array}$ & $\begin{array}{l}0.988 \\
0.631\end{array}$ & $\begin{array}{l}0.003 \\
0.007\end{array}$ & $\begin{array}{l}a>0\left(F_{1,88}=5.26, \mathrm{p}=0.021\right) \\
a>0\left(F_{1,66}=32.32, \mathrm{p}<0.001\right)\end{array}$ & $\begin{array}{l}\text { VB } \\
\text { VB }\end{array}$ & $\begin{array}{l}\text { VB or BS } \\
\text { VB }\end{array}$ \\
\hline $\begin{array}{l}\text { Istigobius } \\
\text { goldmanni }\end{array}$ & $\begin{array}{l}\mathrm{M} \\
\mathrm{F}\end{array}$ & $\begin{array}{l}3.480 \\
3.014\end{array}$ & $\begin{array}{l}-0.012 \\
-0.005\end{array}$ & $\begin{array}{l}a<0\left(F_{1,76}=4.70, \mathrm{p}=0.033\right) \\
a=0\left(F_{1,62}=1.62, \mathrm{p}=0.208\right)\end{array}$ & $\begin{array}{l}\text { Exp } \\
\text { Lin }\end{array}$ & $\begin{array}{l}\mathrm{BS} \\
\mathrm{BS}\end{array}$ \\
\hline $\begin{array}{l}\text { Amblygobius } \\
\text { bynoensis }\end{array}$ & All data & 1.979 & -0.001 & $a=0\left(F_{1,139}=1.15, \mathrm{p}=0.285\right)$ & Lin & VB or BS \\
\hline $\begin{array}{l}\text { Amblygobius } \\
\text { phalaena }\end{array}$ & All data & 1.096 & 0.005 & $a>0\left(F_{1,118}=4.08, \mathrm{p}=0.046\right)$ & VB & VB or BS \\
\hline $\begin{array}{l}\text { Valenciennea } \\
\text { muralis }\end{array}$ & All data & 1.065 & 0.009 & $a=0\left(F_{1,126}=2.48, \mathrm{p}=0.118\right)$ & Lin & VB or BS \\
\hline
\end{tabular}

Table 4. Comparison of 4 growth models fitted to the size-at-age data for 5 species of coral reef goby. Presented are the residual sum of squares (RSS), coefficient of determination $\left(\mathrm{r}^{2}\right)$, and parameter estimates (see 'Materials and methods' for parameter definitions). VBGF: von Bertalanffy growth function; BS: Broken Stick. $x_{0}$ : breakpoint

\begin{tabular}{|c|c|c|c|c|c|c|c|c|c|c|c|c|c|}
\hline & \multirow{3}{*}{$\begin{array}{l}\text { Growth } \\
\text { model }\end{array}$} & \multirow{3}{*}{ RSS } & \multirow[t]{3}{*}{$r^{2}$} & \multicolumn{10}{|c|}{ - Parameter estimates: } \\
\hline & & & & \multicolumn{3}{|c|}{ VBGF/Richards } & \multicolumn{2}{|c|}{ Power } & \multirow[b]{2}{*}{$b$} & \multirow[b]{2}{*}{$d$} & \multirow{2}{*}{$\begin{array}{c}-\mathrm{BS} \\
a\end{array}$} & \multirow[b]{2}{*}{ C } & \multirow[b]{2}{*}{$x_{0}$} \\
\hline & & & & $L_{\infty}$ & $k$ & $t_{0}$ & a & $b$ & & & & & \\
\hline \multirow{4}{*}{$\begin{array}{l}\text { Asterropteryx } \\
\text { semipunctatus } \\
\text { males }(\mathrm{n}=92)\end{array}$} & VBGF & 590 & 0.978 & 77.1 & 0.003 & 3.4 & - & - & - & - & - & - & \\
\hline & Richards & 651 & 0.975 & 58.6 & 0.007 & 132.1 & - & - & - & - & - & - & \\
\hline & Power & 715 & 0.973 & - & - & - & 0.519 & 0.767 & - & - & - & - & \\
\hline & BStick & 640 & 0.976 & - & - & - & - & - & 0.20 & 0.10 & -1.25 & 10.88 & 121.3 \\
\hline \multirow{4}{*}{$\begin{array}{l}\text { Asterropteryx } \\
\text { semipunctatus } \\
\text { females }(\mathrm{n}=70)\end{array}$} & VBGF & 269 & 0.976 & 47.2 & 0.006 & 11.2 & - & - & - & - & - & - & \\
\hline & Richards & 278 & 0.975 & 42.5 & 0.011 & 90.2 & - & - & - & - & - & - & \\
\hline & Power & 552 & 0.949 & - & - & - & 0.799 & 0.668 & - & - & - & - & \\
\hline & BStick & 447 & 0.955 & - & - & - & - & - & 0.20 & 0.06 & -1.25 & 15.31 & 118.3 \\
\hline \multirow{4}{*}{$\begin{array}{l}\text { Istigobius } \\
\text { goldmanni } \\
\text { males }(\mathrm{n}=80)\end{array}$} & VBGF & 1125 & 0.935 & 98.1 & 0.003 & -9.6 & - & - & - & - & - & - & \\
\hline & Richards & 1156 & 0.934 & 70.8 & 0.007 & 123.5 & - & - & - & - & - & - & \\
\hline & Power & 1144 & 0.934 & - & - & - & 0.812 & 0.732 & - & - & - & - & \\
\hline & BStick & 1111 & 0.935 & - & - & - & - & - & 0.26 & 0.13 & -0.94 & 12.72 & 104.4 \\
\hline \multirow{4}{*}{$\begin{array}{l}\text { Istigobius } \\
\text { goldmanni } \\
\text { females }(\mathrm{n}=66)\end{array}$} & VBGF & 771 & 0.909 & 64.8 & 0.004 & -6.1 & - & - & - & - & - & - & \\
\hline & Richards & 819 & 0.902 & 54.9 & 0.009 & 87.8 & - & - & - & - & - & - & \\
\hline & Power & 778 & 0.906 & - & - & - & 1.042 & 0.674 & - & - & - & - & \\
\hline & BStick & 685 & 0.919 & - & - & - & - & - & 0.26 & 0.11 & -0.94 & 15.07 & 104.2 \\
\hline \multirow{4}{*}{$\begin{array}{l}\text { Amblygobius } \\
\text { bynoensis } \\
(\mathrm{n}=143)\end{array}$} & VBGF & 15336 & 0.806 & 117.1 & 0.004 & 7.3 & - & - & - & - & - & - & \\
\hline & Richards & 16015 & 0.794 & 95.0 & 0.009 & 112.4 & - & - & - & - & - & - & \\
\hline & Power & 15662 & 0.796 & - & - & - & 1.071 & 0.761 & - & - & - & - & \\
\hline & BStick & 14324 & 0.819 & - & - & - & - & - & 0.48 & 0.19 & -8.25 & 23.69 & 110.1 \\
\hline \multirow{4}{*}{$\begin{array}{l}\text { Amblygobius } \\
\text { phalaena } \\
(\mathrm{n}=122)\end{array}$} & VBGF & 6820 & 0.908 & 114.4 & 0.005 & 21.1 & - & - & - & - & - & - & \\
\hline & Richards & 7006 & 0.905 & 101.1 & 0.010 & 102.8 & - & - & - & - & - & - & \\
\hline & Power & 8307 & 0.882 & - & - & - & 1.452 & 0.718 & - & - & - & - & \\
\hline & BStick & 7100 & 0.904 & - & - & - & - & - & 0.33 & 0.14 & 3.95 & 44.73 & 214.6 \\
\hline \multirow{4}{*}{$\begin{array}{l}\text { Valenciennea } \\
\text { muralis } \\
(\mathrm{n}=130)\end{array}$} & VBGF & 14856 & 0.806 & 106.1 & 0.007 & 14.1 & - & - & - & - & - & - & \\
\hline & Richards & 15303 & 0.798 & 100.1 & 0.012 & 81.3 & - & - & - & - & - & - & \\
\hline & Power & 15765 & 0.787 & - & - & - & 2.525 & 0.636 & - & - & - & - & \\
\hline & BStick & 14803 & 0.811 & - & - & - & - & - & 0.47 & 0.17 & 0.73 & 42.41 & 138.9 \\
\hline
\end{tabular}



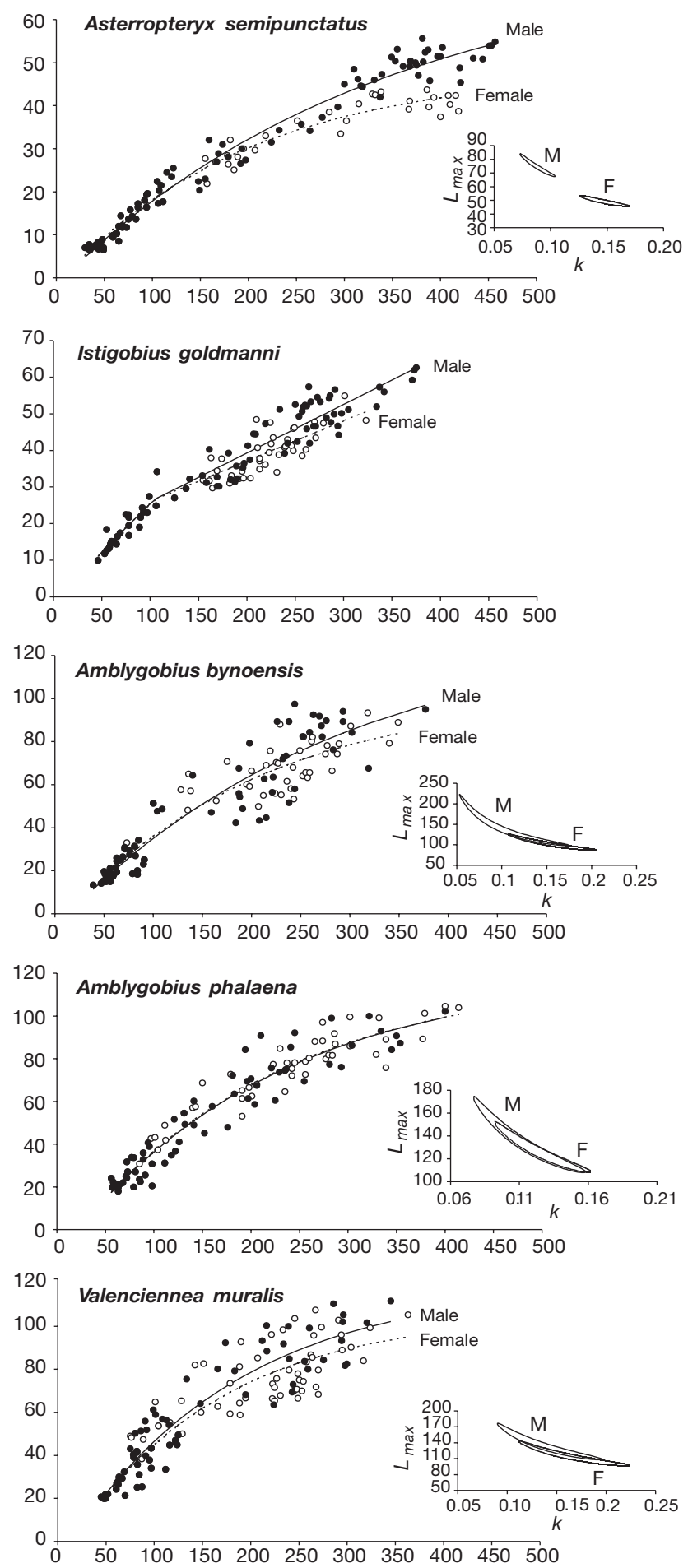

Fig. 6. Sex-specific comparison of growth and life-span. Broken Stick regression (Istigobius goldmanni) and von Bertalanffy growth function (other 4 species) fitted to male $(\bullet)$ and female (O) size-at-age data. Unsexed juveniles used in both male and female data sets. Inlaid plots are $95 \%$ confidence ellipses generated for estimates of $k$ and $L_{\infty}$ from the von Bertalanffy growth function. Note that the scale differs on the $y$-axis ments to much narrower increments for an extended period of time, before the increments widened again. When the timing of the narrowing events was related to month of the year, they always occurred at the onset of the cooler, winter seawater temperatures. The extent to which the season of predominant growth affected growth rate and contributed to the large variability in size-at-age for this species was investigated. Although data for individuals $>150$ d old were limited for the summer season, non-overlapping $95 \%$ confidence ellipses generated for the parameters $k$ and $L_{\infty}$ (Fig. 7, inlaid plot) indicated significant betweenseason differences in the values of these 2 parameters.
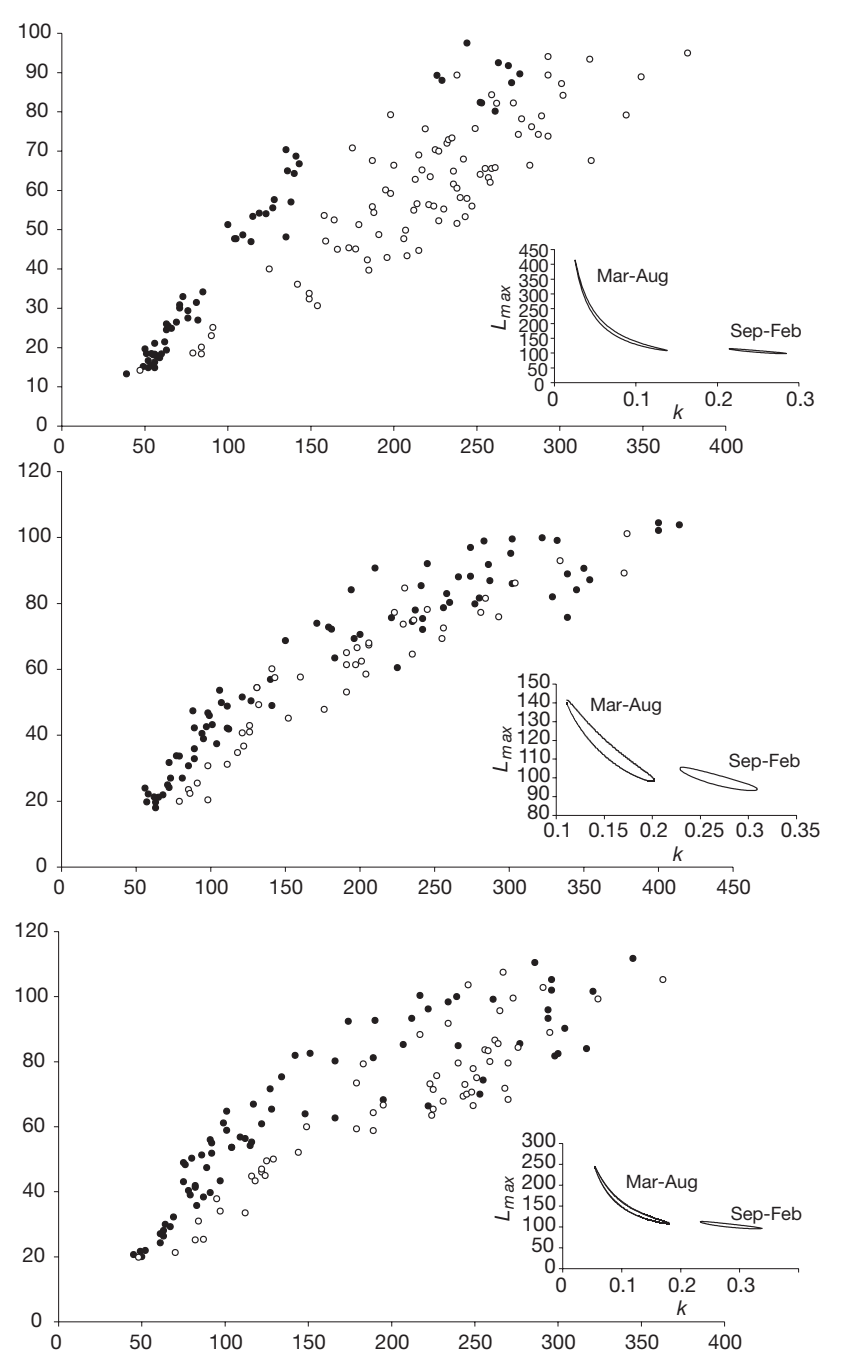

Fig. 7. Size-at-age for Amblygobius bynoensis, A. phalaena and Valenciennea muralis that had grown wholly or predominantly through September to February (•) or March to August (O). Inlaid plots are $95 \%$ confidence ellipses generated for estimates of $k$ and $L_{\infty}$ from the von Bertalanffy growth function 
Generally, individuals that had grown wholly or predominantly through the summer months (September to February) had attained a significantly larger size at a given age than individuals that had grown wholly or predominantly through the winter months (March to August) (Fig. 7). However, there was still substantial within-season variation in size-at-age for individuals growing predominantly through the winter months (Fig. 7).

The data set for summer-growing adults of Amblygobius phalaena and Valenciennea muralis was much larger than that for $A$. bynoensis, and seasonal differences in growth rates of the 2 former species were most apparent for individuals $<130$ and $<150 \mathrm{~d}$ old, respectively (Fig. 7). Even so, non-overlapping $95 \%$ confidence ellipses generated for $k$ and $L_{\infty}$ indicated that seasonal differences in growth rate resulted in significant seasonal differences in these 2 growth parameters (Fig. 7, inlaid plots).

Seasonal differences in growth rates were clearly evident for juveniles of all 3 species. Juveniles growing through summer exhibited a significantly higher growth rate than winter-growing individuals (Amblygobius bynoensis, mean growth rate of 0.54 and $0.29 \mathrm{~mm} \mathrm{~d}^{-1}$ for summer and winter growth respectively, ANCOVA: $F_{1,61}=102.14, \mathrm{p}<0.001$; A. phalaena, 0.63 and $0.45 \mathrm{~mm} \mathrm{~d}^{-1}, F_{1,37}=95.22, \mathrm{p}<0.001$; Valenciennea muralis, 0.61 and $0.42 \mathrm{~mm} \mathrm{~d}^{-1}, F_{1,57}=107.64, \mathrm{p}<$ 0.001). These seasonal differences in growth rates translate to an average of $25 \mathrm{~mm}$ (A. bynoensis), $18 \mathrm{~mm}$ (A. phalaena) and $19 \mathrm{~mm}$ (V. muralis) difference in size after a period of $100 \mathrm{~d}$.

The data set for Asterropteryx semipunctatus and female Istigobius goldmanni was not conducive to detailed examination of seasonal differences in growth rates. Suitable data were available for male I. goldmanni, and ANCOVA indicated that males growing predominantly through summer had significantly higher growth rates than males growing predominantly through winter $\left(F_{1,49}=61.12, \mathrm{p}<0.001\right)$.

\section{DISCUSSION}

The 5 coral reef gobies in this study were all smallbodied and all exhibited a relatively short maximum life-span and rapid growth rates. Maximum life-span was from 11 to $16 \mathrm{mo}$, and each species attained ca. $2 / 3$ of its maximum size by half of its expected maximum life-span. Therefore, it appears that their patterns of growth and life-span conform to traditional concepts of life-history theory.

The pattern of growth of all 5 coral reef gobies differed considerably from that exhibited by other relatively small, but long-lived (up to $32+$ yr old) coral reef fishes, such as certain acanthurids (e.g. Choat \& Axe 1996, Hart \& Russ 1996) and pomacentrids (e.g. Meekan et al. 2001). These long-lived species tend to attain an asymptotic size very quickly (within 2 to 6 yr) and thus spend much of their life-span (often $>75 \%$ ) at that size. In contrast, all 5 coral reef gobies invested in somatic growth throughout much or all of their lifespan and spent relatively little or no time at asymptotic size. While there was evidence that growth began to attenuate in the oldest individuals of 4 species, Istigobius goldmanni clearly exhibited linear adult growth with no signs of an asymptotic size. Rapid nonasymptotic growth has also been noted for Istigobius decoratus, a short-lived ( $<1 \mathrm{yr})$ goby collected from the lagoon at Lizard Island, Great Barrier Reef (Kritzer 2002). Similarly, the intertidal Hawaiian goby Bathygobius coalitus exhibited a linear pattern of growth for at least the first 9 mo of life, with no difference in growth rate between immature and mature gobies (Shafer 1998). Furthermore, size-at-age data presented for a range of temperate gobies also indicates non-asymptotic growth (Grossman 1979, Bouchereau \& Guelorget 1998 and see Kritzer 2002). It seems, therefore, that non-asymptotic growth may be relatively common among both tropical and temperate water gobies.

Long-lived reef fishes often have a growth pattern characterised by rapid growth to asymptotic size and sexual maturity, followed by a relatively long period of reproductive activity, but little additional somatic growth (Choat \& Robertson 2002). This growth pattern may reflect a physiological trade-off between growth and reproduction. Trade-offs play a central role in lifehistory theory, and a physiological trade-off between growth and reproduction is expected where these 2 processes compete directly for a limited amount of energy (Begon \& Mortimer 1981, Partridge \& Harvey 1988, Stearns 1992). However, circumstances may arise where a trade-off between growth and reproduction is minimised or does not occur. For example, energy allocated to reproduction may not entail a growth cost if there were limits to the rate at which energy can be diverted into the somatic tissues (Roff 1992). When fed the same rations, non-reproducing female guppies grew more than reproductively active females, but most of the growth was in the form of fat reserves and not somatic protein growth (Reznick 1983, cited by Wootton 1998). Alternatively, on reaching sexual maturity, a reproductive individual might be able to acquire sufficient additional energy to cover the energetic costs of reproduction, either by an ontogenetic shift in diet to a more profitable or higher quality food source (e.g. MacNeill \& Brandt 1990, McCormick 1998), or by an increase in feeding rate. However, increased foraging time may result in increased predation risk, potentially resulting in a trade- 
off between growth or reproduction and longevity. While the growth rate of the 5 study species decreased following maturation, investment in somatic growth continued for much or all of the adult life-span. Therefore, they appear able to acquire sufficient energy to satisfy demands for both growth and reproduction. This capacity to continue somatic growth may come at a cost of reduced longevity, as evidenced by their relatively short life-spans.

For the 5 study species, continued investment in somatic growth may potentially result in reproductive benefits for both sexes. A positive relationship between body size and fecundity (Hernaman 2003) means that females can maximise both current and future batch fecundity by continued somatic growth. While males do not need a large body size to accommodate testes capable of fertilising a large number of eggs, continued investment in somatic growth may increase their reproductive success through the competitive advantage of large body size in both intra(Grossman 1980, Yanagisawa 1982, Breitburg 1987, Lindström 1992a,b, Forsgren et al. 1996) and interspecific (Breitburg 1987, Robertson 1996) competition for resources (e.g. nest sites, mates, food, territory). Intraspecific competition for nest sites and mates has been recorded for the polygynous Asterropteryx semipunctatus and Istigobius goldmanni (Hernaman 2003), with a large body size providing a competitive advantage in contests over those resources. Intraspecific competition for nest sites was not evident for the monogamous pair-spawning Valenciennea muralis, Amblygobius bynoensis and Amblygobius phalaena (Hernaman 2003). However, mate defence by both sexes was observed occasionally and continued investment in growth may provide a size benefit in contests over mates. Body size influences mate selection in other monogamous coral reef gobies, with both males and females preferring larger partners (Reavis 1997b, Takegaki \& Nakazono 1999) and pair bonds being broken when a mate became available that was larger than the current partner (Takegaki \& Nakazono 1999). Thus, investment of energy in somatic growth is likely to provide reproductive benefits for both sexes of all 5 study species.

Female Asterropteryx semipunctatus and Istigobius goldmanni grew more slowly and attained smaller maximum sizes than males. One explanation is that females expend proportionally more energy on the production of gametes than males (e.g. Newman et al. 1996), and this extra energy requirement is at the expense of somatic growth. Egg production can constitute a considerable drain on energy reserves (Kamler 1992). For example, in female Pomatoschistus microps, 28 to $44 \%$ of the dietary energy content is devoted to egg production (Rogers 1988, cited in Magnhagen
1993). Thus, for the 5 study species that spawn at frequent intervals over the summer months (authors' pers. obs.), sex-specific differences in the cost of gamete production could underlie differences in growth rate between sexes. However, sex-specific differences in growth were not apparent for Valenciennea muralis, Amblygobius bynoensis or Amblygobius phalaena. This disparity among species may be related to interspecific differences in male egg-guarding behaviour. The eggs of $V$. muralis, A. bynoensis and A. phalaena are laid in 1 large cluster, and males appear to spend much of the egg-guarding period fanning the egg mass (Hernaman 2003). Males did not leave the nest site during egg-guarding and did not feed during this time. In contrast, A. semipunctatus and I. goldmanni eggs are deposited in a monolayer, extensive egg fanning was not observed, and males fed near the shelter site during egg-guarding (Hernaman 2003). Thus, the extensive and prolonged egg-fanning activities of $V$. muralis, A. phalaena and A. bynoensis males, combined with the absence of feeding during this time, may result in a relatively higher energetic cost of brood care, compared to that experienced by male A. semipunctatus and I. goldmanni, that is equivalent to the extra energetic cost of egg production in females.

The mating system may also contribute to sexspecific differences in growth rate and maximum size in some species. Sex-specific differences in growth rate were evident for the 2 polygamous species and absent for the 3 monogamous pair-spawning species. This pattern could be related to differences in mate competition associated with each of these mating systems. In monogamous gobies, body size of both males and females appears to be important in mate selection and the stability of the pair bond (Reavis \& Barlow 1998). In contrast, for the 2 polygynous species, intrasexual competition for mates and nest sites is likely to be much stronger among males than females (Emlen \& Oring 1977, Warner 1984). Therefore, there may be a selective premium to rapid male growth and large size in the 2 polygynous species.

The fast growth rates and short life-span often exhibited by small fishes are thought to be the functional response of a high level of unpredictable mortality across the entire life-span (Miller 1996). Although there are a variety of causes of mortality in fish (e.g. reproductive demands, senescence and parasitism; Grossman 1979), predation is likely to be the primary agent of mortality in small species (Pauly 1980, Miller 1984, Munday \& Jones 1998). Coral reef gobies are predated upon by a wide range of demersal and mobile piscivorous fishes (Sweatman 1984, Parrish et al. 1986, Norris \& Parrish 1988, Kingsford 1992, Clark et al. 2000), and might also be vulnerable to predation by sea snakes, invertebrates (e.g. octopus) and shore 
birds. Therefore, the short maximum life-span of all 5 study species is likely to reflect their vulnerability to predation by a wide range of predators.

Munday \& Jones (1998) suggested that patterns of habitat use and predation risk might have a substantial influence on the maximum life-span of small fishes. Small temperate gobies show 2 divergent life-history strategies (Grossman 1979), which may be linked to the mortality rate associated with habitat type (Miller 1996). Nektonic species and those associated with open sandy habitats have a short life-span of $<3$ yr (Fig. 8), presumably because they experience a high risk of predation (Miller 1984). In contrast, cryptobenthic and burrow-dwelling species have relatively long lives of 7 to 11 yr (Fig. 8), presumably because they experience a lower risk of predation (Miller 1984). These differences in maximum life-span are often unrelated to differences in maximum size (Fig. 8, and see Miller 1979).

Although information for tropical gobies is limited, the available data suggest that gobies with similar patterns of habitat use to the 5 study species are also short-lived. For example, Coryphopterus glaucofraenum and Istigobius decoratus, that attain a similar maximum size and occur in similar habitats to I. goldmanni, have a maximum life-span of $<1$ yr (Forrester 1995, Kritzer 2002). Gobies that utilise burrows for shelter also have similar maximum life-spans to the 3 species in the current study that shelter in burrows. For example, Amblyeletoris japonica and Valenciennea strigata both have a maximum life-span of $<2 \mathrm{yr}$ (Yanagisawa 1982, Reavis 1997a). In contrast, more

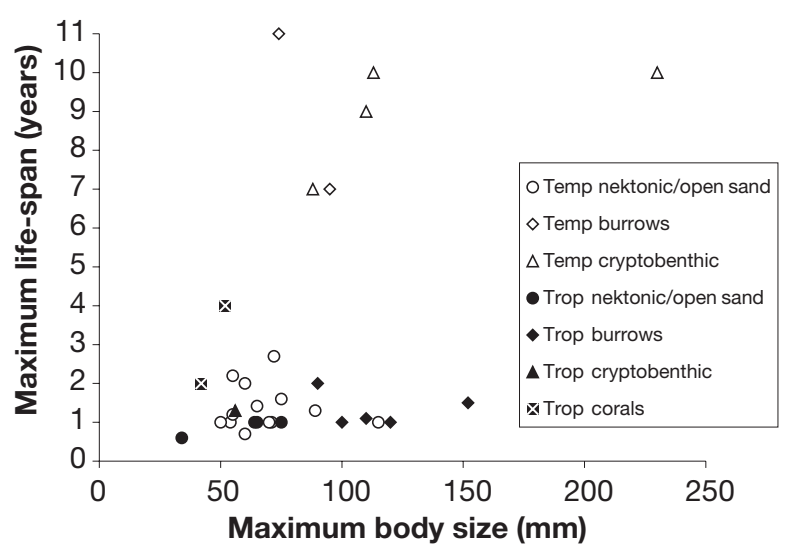

Fig. 8. Relationship between maximum body size and maximum life-span for a suite of tropical (Trop) and temperate (Temp) gobies with different patterns of habitat use. Data derived from: Miller (1961, 1979, 1984), Gibson (1970), Grossman (1979), Yanagisawa (1982), Moreira et al. (1991), Arruda et al. (1993), Magnhagen (1993), Forrester (1995), Gill et al. (1996), Kuwamura et al. (1996), Iglesias et al. (1997), Reavis (1997b), Sano (1997), Bouchereau \& Guelorget (1998), Robertson \& Kaufmann (1998), Kovacic (2001), Munday (2001), Kritzer (2002), and Mazzoldi et al. (2002) and present study cryptic gobies such as obligate coral-dwelling gobies have longer maximum life-spans. For example, Paragobiodon echinocephalus can live for > 2 yr (Kuwamura et al. 1996) and Gobiodon histrio can live at least 4 yr (Munday 2001).

A comparison between temperate and tropical gobies suggests that nektonic and open sand species have similarly short lives in both regions (Fig. 8), probably because high rates of predation drive the lifehistory traits of all these species. In contrast, temperate burrowing and cryptobenthic species tend to be longer-lived than similar sized tropical species with the same behaviour. This difference may reflect fundamental differences in life-history traits among latitudes. Choat \& Robertson (2002) described, for 2 species of acanthurid fishes, a similar relationship between maximum age and latitude to that observed here, and concluded that this pattern may be linked to latitudinal variation in reproductive rates. The capacity to reproduce successfully throughout the year in the tropics may select for short life-spans, whereas the truncation of reproduction to just a few months in cooler waters may select for longer life-spans. Alternatively, there may be an intrinsic association between growth rates and longevity, such that slow growth in cool, high-latitude waters leads to a greater maximum age, whereas fast growth in warm, low latitude waters produces a shorter maximum age (Pauly 1980). However, further studies are required on a range of species in each geographic locale to examine interspecific variation and to separate phylogenetic relationships from latitudinal differences.

Seasonal variation in growth rate was evident for several of the study species. Individuals growing wholly or predominantly through the summer had attained a significantly larger size for a given age than individuals growing wholly or predominantly through the winter. This seasonal difference in growth rate was most pronounced in juveniles, suggesting that the season of settlement may have a significant impact on the timing of maturation, the probability of survival to maturation and reproductive output/success. Reproductive activity was highest during the summer months, but reproductively active females were also found in winter. Thus, recruitment to the adult habitat is likely to occur during both summer and winter. If the timing of maturation is dependent on size, juveniles settling during early summer will attain that size in a shorter time than juveniles settling during early winter. Thus, the time to first reproduction may be relatively shorter in summer-recruiting individuals. Faster growth, and thus a relatively larger body size, may also affect reproductive output because of the effects of body size on fecundity and contests over resources, such as nest sites and reproductive mates. 
Acknowledgements. We thank J. H. Choat for his support of the project and for providing logistical support at James Cook University. We also thank M. Boyle, P. Brewin and D. Craig for field assistance; W. Robbins for advice on otolith preparation; J. Ackerman, J. Kritzer and W. Robbins for valuable discussions on growth models; 3 anonymous reviewers for constructive comments. B. Niven, Department of Maths and Statistics, University of Otago, provided statistical advice. This study was funded by a University of Otago Research Grant awarded to K. Probert (Department of Marine Science, University of Otago) and by Divisional Funding (Department of Marine Science, University of Otago), a PADI Aware Research Grant, and a Commonwealth Postgraduate Scholarship awarded to V.H.

\section{LITERATURE CITED}

Ackerman JL, Bellwood DR (2000) Reef fish assemblages: a re-evaluation using enclosed rotenone stations. Mar Ecol Prog Ser 206:227-237

Arruda LM, Azevedo JN, Neto AI (1993) Abundance, agestructure and growth, and reproduction of gobies (Pisces; Gobiidae) in the Ria de Aveiro Lagoon (Portugal). Estuar Coast Shelf Sci 37:509-523

Begon M, Mortimer M (1981) Population ecology: a unified study of animals and plants. Blackwell Scientific Publications, London

Blueweiss L, Fox H, Kudzma V, Nakashima D, Peters R, Sams S (1978) Relationships between body size and some life history parameters. Oecologia 37:257-272

Bouchereau JL, Guelorget O (1998) Comparison of 3 Gobiidae (Teleostei) life history strategies over their geographical range. Oceanol Acta 21:503-517

Breitburg DL (1987) Interspecific competition and the abundance of nest sites: factors affecting sexual selection. Ecology 68:1844-1855

Campana SE (2001) Accuracy, precision and quality control in age determination, including a review of the use and abuse of age validation methods. J Fish Biol 59:197-242

Charnov EL (1993) Life history invariants: some explorations of symmetry in evolutionary ecology. Oxford University Press, Oxford

Chen Y, Jackson DA, Harvey HH (1992) A comparison of von Bertalanffy and polynomial functions in modelling fish growth data. Can J Fish Aquat Sci 49:1228-1235

Choat JH, Axe LM (1996) Growth and longevity in acanthurid fishes; an analysis of otolith increments. Mar Ecol Prog Ser 134:15-26

Choat JH, Robertson DR (2002) Age-based studies. In: Sale PF (ed) Coral reef fishes: dynamics and diversity in a complex ecosystem. Academic Press, San Diego, p 57-80

Clark E, Stoll MJ, Alburn TK, Petzold R (2000) Mound-building and feeding behaviour of the twostripe goby, Valenciennea helsdingenii, in the south Red Sea. Environ Biol Fish 57:131-141

Emlen ST, Oring LW (1977) Ecology, sexual selection and the evolution of mating systems. Science 197:215-223

Forrester GE (1995) Strong density-dependent survival and recruitment regulate the abundance of a coral reef fish. Oecologia 103:275-282

Forsgren E, Kvarnemo C, Lindström K (1996) Mode of sexual selection determined by resource abundance in two sand goby populations. Evolution 50:646-654

Gibson RN (1970) Observations on the biology of the giant goby Gobius cobitis Pallas. J Fish Biol 2:281-288

Gill HS, Wise BS, Potter IC, Chaplin JA (1996) Biannual spawning periods and resultant divergent patterns of growth in the estuarine goby Pseudogobius olorum: temperature-induced? Mar Biol 125:453-466

Gladstone W, Westoby M (1988) Growth and reproduction in Canthigaster valentini (Pisces, Tetraodontidae): a comparison of a toxic reef fish with other reef fishes. Environ Biol Fish 21:207-221

Grossman GD (1979) Demographic characteristics of an intertidal bay goby (Lepidogobius lepidus). Environ Biol Fish 4: $207-218$

Grossman GD (1980) Food, fights, and burrows: the adaptive significance of intraspecific aggression in the bay goby (Pisces: Gobiidae). Oecologia 45:261-266

Gust N, Choat JH, Ackerman JL (2002) Demographic plasticity in tropical reef fishes. Mar Biol 140:1039-1051

Hart AM, Russ GR (1996) Response of herbivorous fishes to crown-of-thorns starfish Acanthaster planci outbreaks. III. Age, growth, mortality and maturity indices of Acanthurus nigrofuscus. Mar Ecol Prog Ser 136:25-35

Hernaman V (2003) A comparative analysis of the life history and ecology of five species of coral reef goby (Teleostei: Gobiidae). PhD thesis, University of Otago, Dunedin

Hernaman V, Munday PL, Schläppy ML (2000) Validation of otolith growth-increment periodicity in tropical gobies. Mar Biol 137:715-726

Hill KT, Radtke RL (1988) Gerontological studies of the damselfish, Dascyllus albisella. Bull Mar Sci 42:424-434

Iglesias M, Brothers EB, Morales-Nin B (1997) Validation of daily increment deposition in otoliths: age and growth determination of Aphia minuta (Pisces: Gobiidae) from the northwest Mediterranean. Mar Biol 129:279-287

Kamler E (1992) Early life history of fish: an energetics approach. Fish and Fisheries Series 4. Chapman \& Hall, London

Kimura DK (1980) Likelihood methods for the von Bertalanffy growth curve. Fish Bull 77:765-776

Kingsford MJ (1992) Spatial and temporal variation in predation on reef fishes by coral trout (Plectropomus leopardus, Serranidae). Coral Reefs 11:193-198

Kovacic M (2001) The biology of Roule's goby in the Kvarner area, northern Adriatic Sea. J Fish Biol 59:795-809

Kritzer JP (2002) Stock structure, mortality and growth of the decorated goby, Istigobius decoratus (Gobiidae), at Lizard Island, Great Barrier Reef. Environ Biol Fish 63:211-216

Kuwamura T, Nakashima Y, Yogo Y (1996) Plasticity in size and age at maturity in a monogamous fish: effect of host coral size and frequency dependence. Behav Ecol Sociobiol 38:365-370

Leis JM, Rennis DS (1983) The larvae of Indo-Pacific coral reef fishes. New South Wales University Press, Sydney, and University of Hawaii Press, Honolulu, in association with The Australian Museum

Lindström K (1992a) The effect of resource holding potential, nest size, and information about resource quality on the outcome of intruder-owner conflicts in the sandgoby. Behav Ecol Sociobiol 30:53-58

Lindström K (1992b) Female spawning patterns and male mating success in the sand goby Pomatoschistus minutus. Mar Biol 113:475-480

MacNeill DB, Brandt SB (1990) Ontogenetic shift in gill raker morphology and predicted prey capture efficiency of the alewife Alosa psuedoharengus. Copeia 1990:164-171

Magnhagen C (1993) Conflicting demands in gobies: when to eat, reproduce, and avoid predators. In: Huntingford F, Torricelli P (eds) Behavioural ecology of fishes, Vol 23. Taylor \& Francis, London, p 79-90

Mazzoldi C, Poltronieri C, Rasotto MB (2002) Egg size 
variability and mating system in the marbled goby Pomatoschistus marmoratus (Pisces: Gobiidae). Mar Ecol Prog Ser 233:231-239

McCormick MI (1998) Ontogeny of diet shifts by a microcarnivorous fish, Cheilodactylus spectabilis: relationship between feeding mechanics, microhabitat selection and growth. Mar Biol 132:9-20

Meekan MG, Ackerman JL, Wellington GM (2001) Demography and age structures of coral reef damselfishes in the tropical eastern Pacific Ocean. Mar Ecol Prog Ser 212: 223-232

Miller PJ (1961) Age, growth, and reproduction of the rock goby, Gobius paganellus L., in the Isle of Man. J Mar Biol Assoc UK 41:737-769

Miller PJ (1979) Adaptiveness and implications of small size in teleosts. Symp Zool Soc Lond 44:263-306

Miller PJ (1984) The tokology of gobioid fishes. In: Potts GW, Wootton RJ (eds) Fish reproduction: strategies and tactics. Academic Press, London, p 120-153

Miller PJ (1996) The functional ecology of small fish: some opportunities and consequences. In: Miller PJ (ed) Miniature vertebrates: the implications of small body size, Vol 69. The Zoological Society of London, Oxford, p 175-199

Moreira F, Costa JL, Almeida PR, Assis C, Costa MJ (1991) Age determination in Pomatoschistus minutus (Pallas) and Pomatoschistus microps (Kroyer) (Pisces: Gobiidae) from the upper Tagus estuary, Portugal. J Fish Biol 39: 433-440

Munday PL (2001) Fitness consequences of habitat use and competition among coral-dwelling fishes. Oecologia 128: 585-593

Munday PL, Jones GP (1998) The ecological implications of small body size among coral-reef fishes. Oceanogr Mar Biol Annu Rev 36:373-411

Munday PL, Wilson SK (1997) Comparative efficacy of clove oil and other chemicals in anaesthetization of Pomacentrus amboinensis, a coral reef fish. J Fish Biol 51: 931-938

Newman SJ, Williams DM, Russ GR (1996) Age validation, growth and mortality rates of the tropical snappers (Pisces: Lutjanidae) Lutjanus adetii (Castelnau, 1873) and L. quinquelineatus (Bloch, 1790) from the Central Great Barrier Reef, Australia. Mar Freshw Res 47:575-584

Newman SJ, Cappo M, Williams DM (2000) Age, growth and mortality of the stripey, Lutjanus carponatatus (Richardson) and the brown-stripe snapper, L. vitta (Quoy and Gaimard) from the central Great Barrier Reef, Australia. Fish Res 48:263-275

Norris JE, Parrish JD (1988) Predator-prey relationships among fishes in pristine coral reef communities. Proc 6th Int Coral Reef Symp 2:107-113

Parrish JD, Norris JE, Callahan MW, Callahan JK, Magarifuji EJ, Schroeder RE (1986) Piscivory in a coral reef fish community. In: Simenstad CA, Cailliet GM (eds) Contemporary studies on fish feeding. Dr. W. Junk Publishers, Dordrecht, p 285-297

Partridge L, Harvey PH (1988) The ecological context of life history evolution. Science 241:1449-1455

Editorial responsibility: Charles Birkeland (Contributing Editor), Honolulu, Hawaii, USA
Pauly D (1980) On the interrelationships between natural mortality, growth parameters, and mean environmental temperature in 175 fish stocks. J Cons Int Explor Mer 39: 175-192

Randall JE, Allen GR, Steene RC (1997) Fishes of the Great Barrier Reef and Coral Sea. Crawford House Publishing, Bathurst

Reavis RH (1997a) The natural history of a monogamous coral-reef fish, Valenciennea strigata (Gobiidae): 1. Abundance, growth, survival and predation. Environ Biol Fish 49:239-246

Reavis RH (1997b) The natural history of a monogamous coral-reef fish, Valenciennea strigata (Gobiidae): 2. Behaviour, mate fidelity, and reproductive success. Environ Biol Fish 49:247-257

Reavis RH, Barlow GW (1998) Why is the coral-reef fish Valenciennea strigata (Gobiidae) monogamous? Behav Ecol Sociobiol 43:229-237

Robertson DR (1996) Interspecific competition controls abundance and habitat use of territorial Caribbean damselfishes. Ecology 77:885-899

Robertson DR, Kaufmann KW (1998) Assessing early recruitment dynamics and its demographic consequences among tropical reef fishes: accommodating variation in recruitment seasonality and longevity. Aust J Ecol 23: $226-233$

Roff DA (1980) A motion for the retirement of the Von Bertalanffy function. Can J Fish Aquat Sci 37:127-129

Roff DA (1992) The evolution of life histories. Chapman \& Hall, London

Sano M (1997) Temporal variation in density dependence: recruitment and postrecruitment demography of a temperate zone sand goby. J Exp Mar Biol Ecol 214:67-84

Schnute J (1981) A versatile growth model with statistically stable parameters. Can J Fish Aquat Sci 38:1128-1140

Shafer DJ (1998) Early life history, growth and settlement dynamics of a tropical reef fish (Gobiidae: Bathygobius coalitus). PhD thesis, University of Hawaii, Honolulu

Stearns SC (1992) The evolution of life histories. Oxford University Press, Oxford

Sweatman HPA (1984) A field study of the predatory behaviour and feeding rate of a piscivorous coral reef fish, the lizardfish Synodus englemani. Copeia 1984(1):187-194

Takegaki T, Nakazono A (1999) Reproductive behavior and mate fidelity in the monogamous goby, Valenciennea longipinnis. Ichthyol Res 46:115-123

Warner RR (1984) Deferred reproduction as a response to sexual selection in a coral reef fish: a test of the life historical consequences. Evolution 38:148-162

Wootton RJ (1998) Ecology of teleost fishes. Kluwer Academic Publishers, Dordrecht

Worthington DG, Doherty PJ, Fowler AJ (1995) Variation in the relationship between otolith weight and age: implications for the estimation of age of two tropical damselfish (Pomacentrus moluccensis and P. wardi). Can J Fish Aquat Sci 52:233-242

Yanagisawa Y (1982) Social behaviour and mating system of the gobiid fish Amblyeleotris japonica. Jpn J Ichthyol 28: 401-422

Submitted: November 2, 2003; Accepted: September 12, 2004 Proofs received from author(s): March 15, 2005 